\title{
REPRESENTASI BENCANA DALAM FOTO SERI “CERITA KLOSET PASCAGEMPA-TSUNAMI PALU" (STUDI ANALISIS SEMIOTIK TERHADAP FOTO SERI KARYA BEAWIHARTA YANG DIMUAT DI BERITASATU.COM)
}

\author{
Dian Aprilianingrum \\ Program Magister Ilmu Komunikasi Universitas Jenderal Soedirman \\ Email: dianaprilia@hotmail.com
}

\begin{abstract}
:
Disaster representation of series photo "Toilet stories after earthquake-tsunami Palu (Analysis Study On series photo by Beawiharta) analyzed by using Barthes semiotics that was about denotation, connotation and myth. Data sources were primary data sources (photographs) and secondary data sources (literature that supports primary data such as dictionaries, internet, thesis, books). The method used in this study is a qualitative research method that is descriptive analysis, i.e. research that provides an objective picture, with Barthes analysis of photo series. This study chose 1 representative photo from 10 photos at the series. The photo showed toilet among debris at Mamboro and Talisse Beach, Palu, Central Sulawesi. The conclusion of the research showed that 1. Photo visualized aftermath by showing contrast between toilet and debris. 2. Photo visualized massive destruction that force citizen to rebuild their life. 3. There is myth cause of earthquake and tsunami.
\end{abstract}

Keywords: Semiotics, photographs, earthquake

\section{A. PENDAhULUAN}

Pada tanggal 28 September 2018 pukul 17.02, Gempa berkekuatan 7,7 SR mengguncang Donggala, Sulawesi Tengah. Gempa tersebut memicu tsunami dengan ketinggian antara 2,2 hingga 11,3 meter yang menerjang area pemukiman di sekitar Pantai Talisse, Palu, dan pantai di Donggala. Akibatnya hampir semua bangunan di sepanjang pantai di Teluk Palu rata tanah dan rusak berat.

Kerugian dan kerusakan akibat bencana alam di Sulawesi Tengah (Sulteng) mencapai Rp 18,48 triliun per 27 Oktober 2018. . Lebih dari 5000 bangunan ambruk dan 66.926 rumah mengalami kerusakan (tempo.co). Sementara itu, data korban hingga 28 Oktober 2018, tercatat 2.086 orang meninggal dunia, sebanyak 1.309 orang hilang dan 4.438 orang mengalami lukaluka.

Menurut humas BNPB Sutopo seperti dilansir dari rri.co.id tanggal 29 September 2019, tingkat kerusakan yang sangat parah di sekitar pantai disebabkan kekuatan tsunami sangat dahsyat "Di tengah laut kecepatannya hingga $400 \mathrm{~km}$ per jam, sehingga ketika menghantam 
daratan, gelombang air sangat tinggi dan kuat, dan daya rusaknya tinggi. Bisa menghancurkan infrastrukur". Dampak kerugian dan kerusakan di sektor permukiman adalah paling besar karena luas dan masifnya dampak bencana.

Untuk menggambarkan dahsyatnya kehancuran yang diakibatkan oleh bencana tersebut, fotografer Reuters Beawiharta memotret sejumlah kloset jongkok yang tersisa pasca gempatsunami di sekitar pantai Mamboro dan Talisse, Palu. Beawiharta menyadari, di antara bangunan yang runtuh, hanya kloset jongkok yang masih tampak utuh. Foto kloset jongkok tersebut disajikan dalam bentuk foto seri yang kemudian dimuat di laman merdeka.com, beritasatu.com dan reuters.com.

Dalam foto jurnalistik, ada dua pendekatan penyajian foto yang dapat digunakan, yaitu foto tunggal (single photo) dan foto jamak (multiple photo). Dengan foto tunggal, fotografer mengkomunikasikan pesannya dalam satu foto yang kemudian dilengkapi caption. Sementara dalam foto jamak, fotografer menggunakan dua foto atau lebih untuk bercerita. Foto jamak biasa disebut sebagai foto cerita (photo stories)

Dalam foto seri, fotografer menggunakan rangkaian foto dengan konsistensi visual yang sama. Foto seri digolongkan dalam bentuk deskriptif. Susunan foto dalam sebuah foto seri bisa ditukar tanpa mengubah isi cerita dan semakin banyak materi foto, maka semakin jelas cerita yang diungkapkan (Wijaya, 2016).

Berdasarkan pemaparan di atas, maka peneliti tertarik untuk mengetahui makna apa yang dihadirkan lewat sajian foto seri "Cerita Kloset Pasca Gempa-Tsunami" karya Beawiharta. Untuk itu, peneliti melakukan riset untuk memahami representasi bencana dalam karya foto seri "Cerita Kloset Pasca Gempa - Tsunami Palu".

\section{B. TINJAUAN TEORITIS}

a. Representasi

Menurut KBBI representasi adalah perbuatan mewakili, keadaan diwakili, apa yang diwakili. Istilah representasi itu sendiri menunjukkan pada bagaimana seseorang, satu kelompok, gagasan atau pendapat itu ditampilkan atau digambarkan dalam pemberitaan.

b. Bencana 
Undang-Undang Nomor 24 Tahun 2007 tentang Penanggulangan Bencana menyebutkan bencana adalah suatu peristiwa yang mengancam dan mengganggu kehidupan manusia yang disebabkan karena faktor alam, faktor non alam, dan faktor manusia.Kejadian tersebut menyebabkan timbulnya korban jiwa, manusia, kerusakan lingkungan, kerugian harta benda,dan dampak psikologis.

Sementara itu Priambodo (2009) menjelaskan bahwa bencana adalah kejadian yang terjadi secara alami, buatan manusia atau campuran dari keduanya dimana kejadiannya tidak dapat diprediksi atau terjadi tiba-tiba sehingga menimbulkan kerusakan dan dampak yang besar terhadap kehidupan manusia. Menurut United Nations Development Programme and Government of Indonesia (2012) fenomena bencana muncul karena adanya komponen pemicu (trigger), ancaman (hazard), dan kerentanan (vulnerability) yang saling berkaitan sehingga menyebabkan munculnya risiko terhadap komunitas dalam suatu wilayah.

\section{c. Foto Seri}

Taufan Wijaya dalam bukunya yang berjudul "Foto Jurnalistik" menyebukan bahwa foto jurnalistik adalah foto yang bernilai berita atau foto yang menarik bagi pembaca tertentu, dan informasi tersebut disampaikan kepada masyarakat sesingkat mungkin (Wijaya, 2014). Sementara itu, menurut Wikipedia, foto jurnalistik diartikan sebagai sebuah bentuk dari jurnalisme (mengumpulkan, menyunting dan memperlihatkan bahan berita untuk publikasi atau penyiaran) yang menggunakan gambar-gambar dalam rangka mengabarkan sebuah berita.

Berdasarkan jumlah foto, foto jurnalistik dibagi menjadi dua, yaitu foto tunggal dan foto jamak. Foto tunggal yang disertai caption merupakan kesatuan foto jurnalistik yang selalu dijumpai di surat kabar (Wijaya, 2014). Pada penyajian foto tunggal, satu gambar dapat berdiri sendiri dan tidak memerluakan bantuan foto lain untuk membangun cerita. Sedangkan penggunaan lebih dari satu foto di dalam jurnalisme biasa dikenal sebagai foto cerita (photo story). Pendekatan bercerita dilakukan dengan menggunakan berapa foto dan tambahan narasi untuk menjelaskan konteks atau latar belakang (Wijaya, 2016).

Menurut Ahmad Salman yang dipaparkan saat workshop foto stori Brantas Photo Workshop (2012), berdasarkan bentuknya, foto cerita bisa dikelompokkan dalam bentuk deskriptif, naratif dan foto esai. Sedangkan berdasarkan cara bertutur, foto cerita dibagi menjadi empat, yaitu: 
a. Diptych yaitu menyandingkan dua gambar untuk memperoleh efek ketiga yang dihasilkan dari interpretasi dan tindak evaluasi pembaca

b. Sequence yaitu penyajian gambar berurutan yang diatur secara kronologis. Dilakukan untuk memperlihatkan pergerakan (aspek sinematografis), menambah kredibilitas dan agar cerita menjadi masuk akal.

c. Block merupakan serangkaian gambar yang masing-masing mampu membentuk dan memperkaya cerita, setiap foto mengisolasi satu aspek yang unik dan menarik secara visual.

d. Series yaitu penyajian foto-foto yang berkaitan dan diatur dengan menggunakan pictorial devices, sinonim visual dan elemen gambar yang sama. Sinonim visual merupakan kesamaan arti, isi editorial atau sudut pandang pada foto yang berbeda-beda. Sedangkan elemen gambar adalah tema, obyek, tokoh, style, mood, perspektif serta teknik kamera yang digunakan dalam sebuah foto. Dalam materi kelas foto jurnalistik di The City University of New York disebutkan bahwa series adalah satu set rangkaian foto seragam yang didesain untuk mengilustrasikan atu poin perbandingan (cuny.edu)

\section{d. Semiotika}

Secara etimologis, semiotika berasal dari kata yunani, "semeion" yang berarti tanda dan secara terminologis, semiotika adalah cabang ilmu yang berurusan dengan pengkajian tanda dan seggala sesuatu yang berhubungan dengan tanda, seperti sistem tanda dan proses yang berlaku bagi tanda (Sobur, 2004:15).

\section{e. Semiologi Barthes}

Salah satu wilayah penting yang dirambah Barthes dalam studinya tentang tanda adalah peran pembaca (The Reader). Barthes beranggapan bahwa peran seorang pembaca (reader) sangat penting, karena akan menunjukkan apakah pesan yang disampaikan melalui sebuah tanda tersebut dapat diterima atau tidak. Barthes memaparkan pengertian denotasi sebagai signifikas tingkat pertama melihat bahwa denotasi memiliki makna yang sebenarnya.

Barthes juga menyebutkan enam prosedur yang memperngaruhi gambar sebagai analogon atau representasi sempurna dari sebuah realitas. Melalui prosedur ini seorang fotografer dapat menentukan berbagai unsur seperti tanda, hubungan, dan lain-lain yang menjadi pertimbangan seseorang dalam membaca foto. Prosedur-prosedur tersebut dibagi 
menjadi dua bagian, yaitu rekayasa langsung yang mempengaruhi realitas itu sendiri dan rekayasa yang termasuk ke dalam wilayah estetis. Dalam rekayasa secara langsung langsung yang memperngaruhi realitas tersebut terdapat trick effect, pose, dan pemilihan objek.

Trick effect adalah suatu proses manipulasi foto secara berlebihan untuk menyampaikan sebuah berita karena terkadang gambar yang diambil tidak sesuai dengan pesan apa yang sebenarnya ingin disampaikan oleh fotografer itu sendiri.

Pose merupakan gaya, posisi, ekspresi dan sikap objek yang terlihat dalam foto. Selanjutnya adalah pemilihan objek yang dilakukan oleh fotografer. Obyek yang dipilih sangat berperan penting dalam penyampaian pesan melalui foto dan dapat menjadi point of interest.

Dalam rekayasa yang kedua juga terdapat tiga bagian, yaitu photogenia (teknik fotografi yang dilakukan oleh fotografer), aestheticism (komposisi gambar yang menimbulkan makna konotasi), dan sintaksis (rangkaian cerita dari isi foto yang ditampilkan).

Sebuah foto tidak hanya dapat dilihat dari makna denotasinya saja kaena foto juga mengandung makna lain di dalamnya, yaitu konotasi dan mitos. Foto juga berada pada tataran komunikasi yang mempunyai unsur lain seperrti teks tertulis, keterangan foto (caption), judul, dan artikel yang mendukung foto tersebut.

Mitos merupakan sebuah sistem komunikasi karena Barthes melihat bahwa mitos merupakan pesan yang disampaikan turun temurun. Mitos tidak dapat dilihat melalui objek pesannya, melainkan dari cara penyampaian pesan tersebut.

Konotasi, walaupun merupakan sifat asli tanda, membutuhkan keaktifan pembaca agar dapat berfungsi. Barthes secara lugas mengulas apa yang sering disebutnya sebagai sistem pemaknaan tataran kedua,yang dibangun di atas sistem lain yang telah ada sebelumnya. Sistem kedua ini oleh Barthes disebut dengan konotatif, yang di dalam buku Mythologies-nya secara tegas ia bedakan dari denotative atau sistem pemaknaan tataran pertama. 


\section{METODE PENELITIAN}

Penelitian ini menggunakan metodologi penelitian kualitatif dengan analisis semiotika Roland Barthes. Penelitian kualitatif bertujuan untuk menjelaskan fenomena dengan sedalamdalamnya tentang apa yang dialami subjek. Metode kualitatif ini juga tidak mengutamakan besarnya populasi dan sampling, sehingga penelitian tersebut bersifat subyektif yang hasilnya bukan untuk digeneralisasikan (Kriyantono, 2008).

\section{HASIL PENELITIAN DAN PEMBAHASAN}

Rangkaian foto seri Cerita Kloset Pasca Gempa-Tsunami karya Beawiharta ini terdiri dari 10 foto kloset jongkok diantara reruntuhan bangunan. Beawiharta merespons kondisi kehancuran akibat tsunami dan gempa di sepanjang pantai Mamboro dan Talise, Palu, Sulawesi Tengah dengan memotret kloset jongkok yang terlihat diantara reruntuhan. Beawiharta menggunakan pendekatan foto seri untuk memperjelas pesan yang disampaikan. Pada foto seri semakin banyak materi foto, maka semakin jelas cerita yang diungkapkan.

Foto-foto yang ditampilkan dalam foto seri memiliki sinonim visual atau homonim visual dan elemen gambar yang sama sehingga dalam penelitian ini akan dianalisis 1 foto dari 10 foto seri karya Beawiharta yang ditampilkan di beritasatu.com. Foto tersebut diteliti dengan menggunakan analisis semiologi Roland Barthes. Foto tersebut dipandang menjadi representasi kehancuran akibat bencana. 
Berikut adalah pembahasan dari salah satu foto yang ditampilkan:

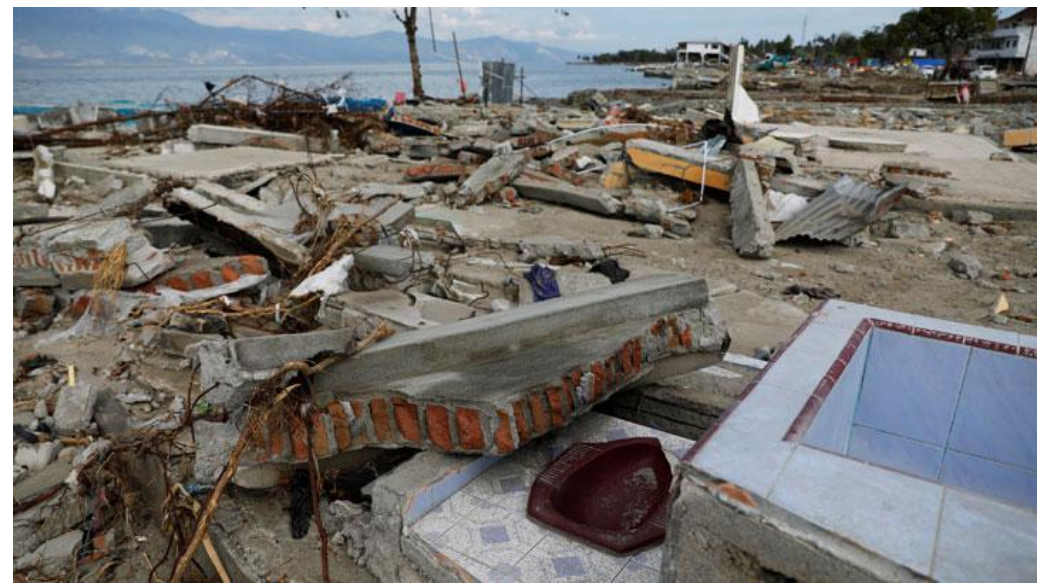

Sebuah toilet tersisa di tengah reruntuhan rumah-rumah yang hancur usai musibah gempa dan tsunami beberapa hari lalu di Pantai Talise, Palu, Sulawesi Tengah

1. Tahap Denotasi

Denotasi berarti makna harfiah atau sesungguhnya. Sedangkan tahap denotasi adalah tahap pemaknaan yang dilakukan secara deskriptif dan literal serta dapat dipahami oleh pembaca tanpa melakukan penafsiran terlebih dahulu. Tahap ini mengidentifikasi hal-hal yang dapat dilihat secara jelas oleh mata. Toilet adalah tempat orang buang kotoran untuk membersihkan sisa-sisa kotoran dari tubuh manusia. Kloset jongkok umumnya digunakan di rumah-rumah warga dengan ekonomi menengah ke bawah. Banyaknya jumlah toilet mengindikasikan banyaknya rumah warga yang dibangun di daerah tersebut.

\section{Tahap Konotasi}

Dalam pandangan Barthes, tahap ini dapat dikemukakan melalui enam cara dalam membaca foto, yaitu:

a. Trick Effect (Memanipulasi Foto) 
Foto diambil dengan memposisikan kloset jongkok sebagai point of interest berada di depan sedangkan puing bangunan terletakdi sekitarnya. Foto ini merupakan salah satu rangkaian foto seri yang dimuat di media massa. Sebagai foto jurnalistik, foto tidak diperbolehkan untuk dimanipulasi secara berlebihan, hanya sebatas cropping dan pengaturan kecerahan gambar. Manipulasi foto dapat mengubah makna sebenarnya dari foto tersebut.

b. Pose

Fotografer menekankan kondisi kloset jongkok yang masih tampak utuh dengan memotretnya sebagai latar depan (foreground) sehingga porsi gambar kloset tampak lebih besar dibadingkan lingkungan di dekatnya Ini menunjukkan bahwa kloset jongkok merupakan obyek utama (point of interest) dari foto tersebut.

c. Objek

Objek dalam foto ini adalah kloset jongkok yang terlihat utuh di antara puing bangunan sehingga terlihat kekontrasan dari situasi yang terekam.

d. Photogenia (teknik foto)

Foto ini diambil menggunakan teknik ruang tajam luas sehingga antara objek kloset jongkok dan puing-puing bangunan, serta lansekap pegunungan di latar belakang (background) tampak sama fokusnya. Ruang tajam luas digunakan untuk memberikan informasi yang lebih lengkap dalam menunjukkan kondisi yang terjadi.

e. Aestheticism (komposisi) 
Komposisi adalah susunan elemen visual dalam foto sehingga foto tampak menarik. Dalam foto ini fotografer mengambil angle dengan memposisikan bak mandi di depan sehingga tampak paling besar. Sementara itu fotografer juga memanfaatkan gris-garis imajiner yang ada untuk memperkuat karya fotonya.

f. Syntax

Dalam foto ini syntax yang dibangun menunjukkan bahwa fotografer mengajak pembaca foto untuk memperhatikan kloset jongkok yang menjadi foreground. Setelah itu baru diperlihatkan bagaimana kondisi sekitar kloset sebagai akibat dari bencana alam gempa-tsunami. Caption yang digunakan memperjelas pesan dari fotografer.

Konotasi berarti makna kiasan. Tsunami dapat dikiaskan dengan kloset yang sama-sama berfungsi dengan aliran air yang deras dan banyak. Kloset digunakan untuk membersihkan kotoran dari tubuh mausia, sedangkan tsunami untuk membersihkan kotoran dari sebuah wilayah.

Banyaknya reruntuhan kloset yang terekam dalam rangkaian foto seri ini menggambarkan padatnya bangunan di sekitar pantai Mamboro dan Talise sebelum bencana gempa-tsunami terjadi. Kerusakan yang massif seperti diperlihatkan dalam foto juga menjadi bukti besarnya dampak bencana terhadap kehidupan di sepanjang Teluk Palu. Masyarakat Palu harus memulai membangun segalanya kembali dari nol karena bencana telah menyapu bersih bangunan dan kehidupan di dalamnya. 
3. Mitos

Mitos merupakan salah satu kebudayaan yang telah ada sejak masa lampau. Mitos dapat berkembang dari bagaimana cara masyarakat menanggapinya. Terjadinya bencana alam selalu dikaitkan dengan mitos yang telah ada sebelumnya. Masih banyak masyarakat yang percaya terhadap mitos walaupun belum diketahui benar atau tidaknya.

Sesaat sebelum terjadinya bencana, pemerintah kota Palu menggelar Festival Nomoni di pinggir pantai Talise. Salah satu agenda festival tersebut adalah mengadakan ritual Balia yaitu mengobati orang sakit menggunakan mantra dan dilakukan oleh seorang ahli.

Masyarakat sekitar beranggapan bahwa festival Palu Nomoni yang diramaikan dengan ritual Balia tersebut mengandung unsur praktik syirik (menyekutukan Tuhan) di dalamnya. Oleh karena itu mereka meyakini bahwa gempa - tsunami Palu dan sekitarnya tidak terlepas dari "hukuman Tuhan" atas ulah manusia yang melakukan praktik syirik tersebut. Karena sudah beberapa kali diadakan Festival Palu Nomoni selalu ada kejadian buruk yang menimpa warga. Hal itu pula yang mengakibatkan kawasan pantai Talise tempat berlangsungnya acara mengalami kehancuran.

Pantai Talise juga disebut sering digunakan sebagai area aktivitas pelacuran. Keberadaan sejumlah hotel dan karaoke disekitar pantai tersebut juga dianggap sebagai area berbuat maksiat. Perbuatan syirik dan maksiat dipandang sebagai kotoran yang harus dibersihkan dari wilayah Palu melalui tsunami 


\section{E. KESIMPULAN}

Kesimpulan yang diperoleh dari hasil penelitian terhadap foto seri kloset jongkok pascagempa-tsunami Palu karya Beawiharta adalah sebagai berikut:

\section{Tahap Denotasi}

Melalui foto Beawiharta tergambar jelas kondisi pantai di Teluk Palu setelah terjadinya bencana yang menimbulkan banyak korban jiwa tersebut. Beawiharta tidak menggunakan manipulasi foto sehingga menunjukkan realita yang sesungguhnya terjadi. Dapat disimpulkan bahwa Beawiharta ingin memberikan informasi secara akurat.Pesan yang disampaikan adalah bahwa bencana dapat menimbulkan dampak yang besar sehingga masyarakat perlu lebih waspada dalam menghadapi bencana yang mungkin akan terjadi lagi.

\section{Tahap Konotasi}

Setelah menganalisa foto diketahui bahwa terdapat makna konotasi pada foto tesebut. Penulis memaknai bahwa bencana alam yang terjadi menimbulkan dampak yang luas baik berupa materi, kerusakan infrastruktur, juga berdampak pada kehidupan para korban. Foto yang menggambarkan kehancuran tersebut menunjukkan masyarakat perlu membangun segalanya kembali.

\section{Mitos}

Bencana gempa-tsunami yang terjadi pada akhir September 2018 tersebut tidak terlepas dari mitos yang berkembang di masyarakat. Dalam foto diperlihatkan bagaimana kuasa Tuhan dalam menegur manusia dengan mendatangkan bencana besar sebagai akibat dari ulah manusia yang menyekutukan-Nya. 


\section{DAFTAR PUSTAKA}

Kriyantono, Rachmat. 2008. Teknis Praktis Riset Komunikasi. Jakarta : Kencana

Priambodo, Arie. 2009. Panduan Praktis Menghadapi Bencana. Yogyakarta: Kanisius.

Sobur, Alex. 2004. Semiotika Komunikasi. Bandung: Remaja Rosdakarya. .2006. Analisis Teks Media : Suatu pengantar untuk Analisis Wacana, Analisis

Semiotik, dan Analisis Framing. Bandung: Remaja Rosdakarya

Sunardi, ST. 2002. Semiotika Negativa. Yogyakarta:Kanal,

Wijaya, Taufan, 2014. Foto Jurnalistik. Jakarta: Gramedia . 2016. Photo Story Handbook. Jakarta: Gramedia . 2018. Literasi Visual. Jakarta: Gramedia

Undang-Undang Republik Indonesia Nomor 24 Tahun 2007 tentang Penanggulangan Bencana.

https://www.beritasatu.com/galeri-foto/9311-cerita-kloset-pascagempatsunami-palu

http://rri.co.id/post/berita/577874/nasional/tsunami_sulteng_korban_di_palu_384_tewas_kebany akan_oleh_tsunami.html

https://nasional.tempo.co/read/1134045/bnpb-gempa-dan-tsunami-palu-merusak-66-926-rumah 